\title{
An Education Framework for Effective Implementation of a Health Information System: Scoping Review
}

Tharshini Jeyakumar $^{1,2}$, BSc, MHI; Sarah McClure ${ }^{1}$, CTDP; Mandy Lowe ${ }^{1,3}$, MSc, OT Reg (Ont); Brian Hodges ${ }^{1,4,5}$, $\mathrm{PhD}$, MD, FRCPC; Katharine Fur ${ }^{1}$, CTDP; Mariquita Javier-Brozo ${ }^{1}$, BASc, RD; Maria Tassone ${ }^{1,6}$, BScPT, MSc; Melanie Anderson ${ }^{1}, \mathrm{BAH}$, MLIS; Tim Tripp ${ }^{1}, \mathrm{BSc}, \mathrm{MLIS}$; David Wiljer ${ }^{1,2,4}, \mathrm{PhD}$

${ }^{1}$ University Health Network, Toronto, ON, Canada

${ }^{2}$ Institute of Health Policy, Management and Evaluation, University of Toronto, Toronto, ON, Canada

${ }^{3}$ Department of Occupational Science and Occupational Therapy, Faculty of Medicine, University of Toronto, Toronto, ON, Canada

${ }^{4}$ Department of Psychiatry, Faculty of Medicine, University of Toronto, Toronto, ON, Canada

${ }^{5}$ Wilson Centre, Toronto, ON, Canada

${ }^{6}$ Department of Physical Therapy, Faculty of Medicine, University of Toronto, Toronto, ON, Canada

${ }^{7}$ Office of Education, Centre for Addiction and Mental Health, Toronto, ON, Canada

\section{Corresponding Author:}

David Wiljer, PhD

University Health Network

190 Elizabeth Street, R. Fraser Elliot Building RFE 3S-441

Toronto, ON, M5G 2C4

Canada

Phone: 14163404800 ext 6322

Email: David.wiljer@uhn.ca

\section{Abstract}

Background: To optimize their use of a new Health Information System (HIS), supporting health care providers require effective HIS education. Failure to provide this education can significantly hinder an organization's HIS implementation and sustainability efforts.

Objective: The aim of this review is to understand the most effective educational strategies and approaches to enable health care providers to optimally use an HIS.

Methods: Ovid MEDLINE, Ovid Embase, EBSCO Cumulative Index to Nursing and Allied Health Literature, and EBSCO Education Resources Information Center were searched to identify relevant papers. Relevant studies were systematically reviewed and analyzed using a qualitative thematic analysis approach.

Results: Of the 3539 studies screened, 17 were included for data extraction. The literature on the most effective approaches to enable health care providers to optimally use an HIS emphasized the importance of investing in engaging and understanding learners in the clinical context, maximizing the transfer of learning to care, and designing continuous and agile evaluation to meet the emerging demands of the clinical environment.

Conclusions: This review supports the advancement of a new HIS learning framework that organizational leaders and educators can use to guide HIS education design and development. Future research should examine how this framework can be translated into practice.

(J Med Internet Res 2021;23(2):e24691) doi: 10.2196/24691

\section{KEYWORDS}

health information system; health care providers; education; learning; patient care 


\section{Introduction}

\section{Background}

Health Information Systems (HISs) have been proposed as one solution in a multipronged organizational approach to transforming the quality of care delivered, increasing patient safety, and reducing health care costs [1]. An HIS is defined as a system designed to integrate data collection, processing, and reporting and the use of health information to influence policy making and improve health service effectiveness and efficiency [2]. This enables the facilitation of health information sharing among multiple authorized custodians across the health care continuum in support of clinical efficiency and optimal quality care [3]. Challenges to HIS implementation can result from staff and care providers being unfamiliar with the system features and functionalities, thus encumbering the ability of staff and providers to use HIS in their work environment most effectively. Given the rapid pace of adoption of digital HISs globally and the skills needed to effectively use HISs in practice, it is crucial to support and educate health care providers at all levels, across all areas of the health system, and as close to implementation as possible, on how the HIS system can be leveraged to improve clinical practice. Simply teaching the system is not sufficient to successfully enable learners (entry-to-practice and practicing health care staff) to use new technology.

As health care organizations respond to budgetary, regulatory, and societal pressures to implement an HIS, care providers are confronted with an ever-increasing technology-enabled care environment [4]. Paradoxically, although the implementation of HISs is meant to create efficiencies, their widespread diffusion and accompanying complexity have been associated with a growing recognition of clinician dissatisfaction and burnout [5]. However, health care providers see education as integral to use technology successfully [4]. On the basis of the model of skill acquisition, Bredfeldt et al [1] determined that educating novices entails more than just imparting knowledge. Further, it is essential to provide education that is pertinent to address learning needs and provide an opportunity to learn the nature of the real setting and its associated variability [1]. It is also imperative to acknowledge learners' expertise and engage them throughout all phases in the development of the educational program [6]. This may be especially true for health sciences students and trainees who may have deeper knowledge of using various technologies, thereby having the potential to play a role of educator or facilitator with supervisors in practice. Furthermore, education may enable care providers and staff to understand the concepts underlying the different HIS tasks as the emerging needs of their clinical practice continuously evolve rather than simply learning the features of an HIS. HIS education can also influence user adoption and the ability of health care providers and staff to effectively use the technology [4]. On the basis of learners' feedback in the study, McAlearney et al [7] noted that staff who received excellent education and hands-on experience with an information technology system adopted realistic expectations and achieved a sense of control within the HIS environment. Adequate education and support, technology literacy, and overall competencies of health providers were identified as critical factors in HIS implementation.

Many information technology users encounter a steep learning curve at the initial stages of implementation and can take several years to become an expert in the features and functions of a system [8]. McLean et al [8] suggested that users' attitudes toward system use in the initial stages could be leveraged to gain valuable insights into how the system will be used in the later stages. Thus, education remains a critical component in understanding the benefits of HISs and attaining value-added use, particularly during the adoption or early stages of implementation [8,9]. Furthermore, to enable ongoing learning in using an HIS adeptly, education strategies will need to be evaluated and refined over time, as education will need to continuously evolve to meet users' needs and comfort level with the HIS [8,9].

In several HIS implementation projects, inadequate HIS education has led to challenges in the adoption and suboptimal use of the system. An example is an electronic health record (EHR) implementation project at Cedars Sinai Hospital, California, where a dearth of staff education contributed to poor adjustment to the new system and created a sense of fear and apprehension [10,11]. Consequently, this lack of education threatened staff autonomy and eventually contributed to the rejection of the HIS and project failure [10,11].

\section{Objectives}

As HISs become an integral part of patient care, building an effective educational strategy may ultimately aid in the successful implementation and sustainment of an HIS. Recognizing the importance of education programs in supporting HIS implementations, this study was conducted to understand the current state of HIS education programs as reported in the academic literature. Specifically, the objective of this study is to establish a foundational understanding of the most effective strategies and approaches to enable individuals to optimally adopt and effectively use and learn from an HIS, both during and postimplementation.

\section{Methods}

\section{Overview}

A scoping review methodological framework adopting the approach by Arksey and O'Malley [12] was used to enhance the reproducibility and reliability of our findings. One of the goals of this approach was to broadly examine a topic area to map key concepts, evidence types, and current gaps in research in a well-defined field using a wide array of literature. This was an ideal starting point to better understand the landscape of research within a specific subject area. To illustrate the scoping review process, the PRISMA (Preferred Reporting Items for Systematic Review and Meta-Analysis) diagram [13], shown in Figure 1, and the PRISMA scoping review checklist, which outlines the important milestones of a scoping review, were used [14] (Multimedia Appendix 1). 
Figure 1. PRISMA (Preferred Reporting Items for Systematic Review and Meta-analysis) flow diagram of scoping review results.

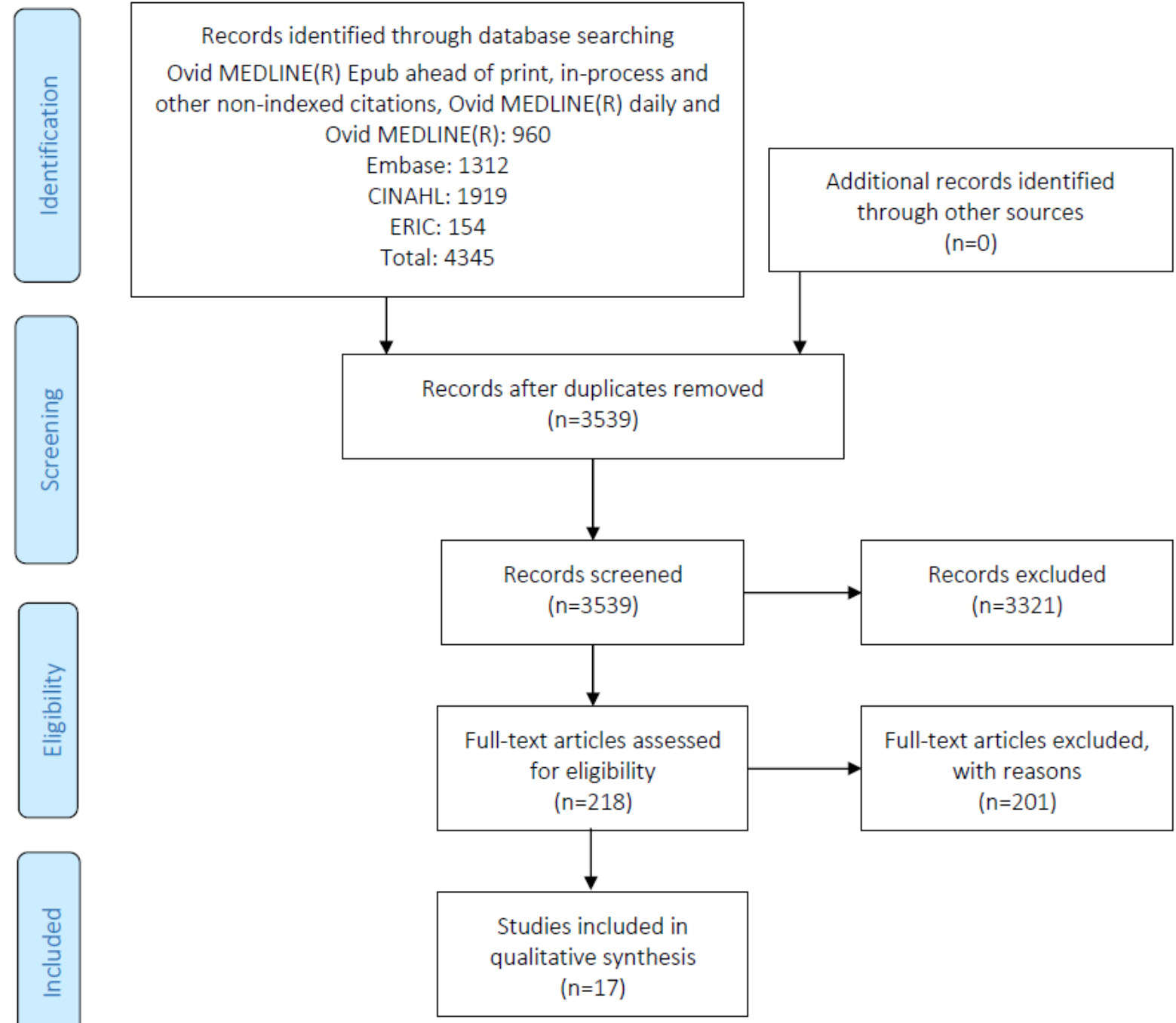

\section{Stage 1: Identifying the Research Questions}

To establish a baseline understanding of the most effective strategies and approaches to enable individuals to optimally use an HIS system in academic literature, this study sought to answer the following questions:

1. What education approaches led to an effective HIS implementation? What are the reported results of classroom-based, web-based, and blended learning in terms of educating staff on HISs?

2. What are the measures and outcomes used to assess the effectiveness of education and its impact on the implementation of the HIS?

3. What are the most effective approaches for enabling individuals to optimally use an HIS? How is education most effectively delivered?

\section{Stage 2: Identifying Relevant Studies}

An iterative process was used to design effective database strategies to identify eligible papers, involving several discussions with information specialists and the research team at our institution. Strategies, including subject headings, keywords, and related terms for HISs; education approaches; and training modalities were designed by a health sciences librarian for each of Ovid MEDLINE, Ovid Embase, EBSCO Cumulative Index to Nursing and Allied Health Literature, and EBSCO Education Resources Information Center and results were downloaded in November 2019 (Multimedia Appendix 2). No date or language limits were applied. HIS was defined in these searches as an electronic medical record (EMR), EHR, medical records systems, computerized medical records, electronic patient records, computer health records, computer medical records, computer hospital records, clinic information systems, electronic health medical records, and electronic hospital medical records. Relevant studies were identified through a title and abstract scan and confirmed via a full-text review. For the study selection, see the PRISMA diagram (Figure 1).

\section{Stage 3: Study Selection}

Peer-reviewed journal papers eligible for inclusion met the following criteria: (1) examined educational approaches (ie, classroom, instructor-led, web-based training, e-learning, and hybrid learning), (2) discussed HIS systems (EMR, EHR, Clinical Information system, etc), (3) discussed the effectiveness 
of different approaches in educating staff to use the HIS, (4) described an educational program related to HIS, and (5) ensured education be conducted in a hospital setting. Initially, only English papers were included; however, as there were no papers found in other languages, no papers were excluded. All study designs, whether quantitative or qualitative studies and papers found in reports and research papers except for viewpoint papers, such as editorials, were included. Studies conducted in an academic setting and papers that did not meet the aforementioned criteria or describe an HIS system were excluded. Five coauthors independently reviewed the paper to determine each study's eligibility, and in cases of uncertainty, a senior reviewer with expertise in the topic of HISs was consulted.

\section{Stage 4: Data Items and Data Collection Process}

A standardized charting form was developed to capture the following domains: study details (type of study, year, and country), the objective of the study, study design (if applicable), study participants, intervention, study outcomes, and main results of the study. The PICO (Patient Problem or Population, Intervention, Comparison or Control, and Outcome) framework was used to capture details of the study, where the study outcomes were categorized using the Kirkpatrick-Barr [15] framework of educational outcomes, shown in Textbox 1. This framework was selected, as it provided a standardized method of categorizing the type of educational outcomes reported by each paper.

Textbox 1. Kirkpatrick-Barr framework of educational outcomes.

Level 1: Learners' reaction

- Learners' perspectives on the learning experience and satisfaction with the educational program [15]

Level 2a: Modification of attitudes and perceptions

- Changes in attitudes and perceptions toward patients or clients and their condition, circumstances, care, and treatment [15]

Level 2b: Acquisition of knowledge and skills

- $\quad$ Changes in knowledge and skills [15]

Level 3: Change in behavior

- Changes in behavior of participants' transfer of learning to their practice setting and changed professional practice [15]

Level 4a: Change in organizational practice

- Wider changes in the organizational practice and provision of care as a result of an education program [15]

Level 4b: Benefits to patients or clients

- Improvements in health or well-being of patients or clients attributable to an education program [15]

\section{Stage 5: Synthesizing and Reporting the Results}

A qualitative narrative review approach was adopted, and the authors independently reviewed all 17 studies. The educational outcomes reported in each paper were categorized using the Kirkpatrick-Barr framework, which also helped inform the thematic analysis. The findings were synthesized, and a thematic analysis approach was used to critically analyze the papers and develop a coding structure. Emerging themes were identified, compared, and consolidated by 3 authors. The consultation phase provided an opportunity to validate the findings and critically examine the inconsistencies or lack of clarity evident across the papers reviewed. Discussions and consultation with content experts within our team enabled us to further iterate and contextualize the themes.

\section{Results}

\section{Search Results}

The initial database search yielded 4345 papers. Once duplicates were removed, titles and abstracts of 3539 unique citations were identified. We screened these papers and identified 218 citations based on broad relevance to the topic area. The 218 abstracts then went through the second round of scrutiny against the inclusion criteria, and 33 papers were selected for full-text review. Following further inspection, 16 papers were excluded, as they did not meet the inclusion criteria. Table 1 describes the characteristics of the studies included in this study. 
Table 1. Study characteristics (N=17).

\begin{tabular}{|c|c|c|}
\hline Study characteristics & Value, n (\%) & References \\
\hline \multicolumn{3}{|l|}{ Country of publication } \\
\hline United States & $12(70)$ & {$[1,4-7,16-22]$} \\
\hline Australia & $1(6)$ & {$[23]$} \\
\hline Namibia and Tanzania & $1(6)$ & {$[24]$} \\
\hline United Kingdom & $1(6)$ & [25] \\
\hline Denmark & $1(6)$ & {$[26]$} \\
\hline The Netherlands & $1(6)$ & {$[27]$} \\
\hline \multicolumn{3}{|l|}{ Research method } \\
\hline Literature review & $3(18)$ & {$[25-27]$} \\
\hline Questionnaire or survey & $4(23)$ & {$[6,19,21,23]$} \\
\hline Semistructured interview & $1(6)$ & [9] \\
\hline Mixed method & $6(35)$ & {$[4,5,16,17,20,22]$} \\
\hline Quasiexperimental & $2(12)$ & {$[1,24]$} \\
\hline Case report & $1(6)$ & {$[18]$} \\
\hline \multicolumn{3}{|l|}{ Year of publication } \\
\hline 2016-2019 & $5(29)$ & {$[5,23-26]$} \\
\hline $2010-2015$ & $9(53)$ & {$[1,4,6,7,16,17,19,22,27]$} \\
\hline 2006-2009 & $3(18)$ & {$[18,20,21]$} \\
\hline \multicolumn{3}{|l|}{ 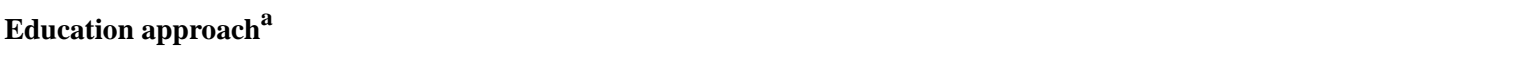 } \\
\hline In-classroom training & $5(38)$ & {$[5,6,16,18,20]$} \\
\hline e-Learning & $1(8)$ & {$[22]^{\mathrm{b}}$} \\
\hline Blended learning & $5(38)$ & {$[1,17,19,23,24]$} \\
\hline Classroom versus blended learning & $1(8)$ & {$[4]$} \\
\hline Simulation training & $1(8)$ & [19] \\
\hline
\end{tabular}

${ }^{\mathrm{a}}$ Literature reviews were excluded.

${ }^{\mathrm{b}}$ Did not provide evaluation outcomes.

\section{Research Question 1: Reported Results of Classroom-Based, Web-Based, and Blended Learning in Terms of Educating Staff on HISs}

On the basis of the thematic analysis, this study identified 3 major themes across the different educational approaches that led to a more effective HIS implementation:
- Invest in engaging and understanding learners in the clinical context

- Maximize the transfer of learning to care

- Continuous and agile evaluation designed to meet the emerging demands of the clinical environment

In addition, the themes addressed in this study encompass fundamental elements that may be used to guide educational design and support developmental expertise in clinical environments (Table 2). 
Table 2. Elements associated with the 3 major themes identified in the thematic analysis.

\begin{tabular}{|c|c|c|}
\hline Theme and element & Definition of element & Studies using an element \\
\hline \multicolumn{3}{|c|}{ Invest in engaging and understanding learners in the clinical context } \\
\hline $\begin{array}{l}\text { Assessment of individual, team, and organization } \\
\text { capabilities }\end{array}$ & $\begin{array}{l}\text { - Assess appropriate learning needs } \\
\text { - Assess computer literacy } \\
\text { - } \quad \text { Ascertain clinical background and role } \\
\text { ing based on the work environment and department needs, } \\
\text { eg, inpatient provider, ambulatory provider) }\end{array}$ & {$[1,16,21,23,26,27]$} \\
\hline \multicolumn{3}{|l|}{ Maximize the transfer of learning } \\
\hline Practice and problem-based learning & $\begin{array}{l}\text { - Use a problem-based approach to learning instead of task- } \\
\text { based learning (ie, learning built on predefined tasks ad- } \\
\text { dressed in clinical practice). } \\
\text { Integrate hands-on experience to enable learner empower- } \\
\text { ment. }\end{array}$ & {$[1,4,6,7,17,23,25,28]$} \\
\hline Integrate learning into practice & 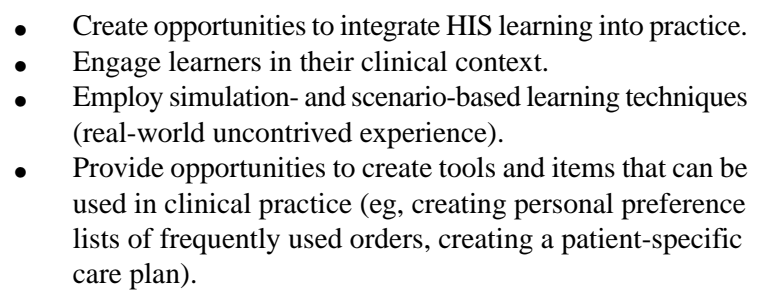 & {$[1,4,16,22,25,26]$} \\
\hline Enhance practice improvement and performance & $\begin{array}{l}\text { Ensure the learning time is as close to the launch of the } \\
\text { HIS as possible. } \\
\text { - Adopt longitudinal approaches to training. } \\
\text { - } \quad \text { ddentify and integrate super users as part of education } \\
\text { - Collaborate with and learn from clinical champions. }\end{array}$ & {$[6,7,17,23,25,26]$} \\
\hline \multicolumn{3}{|c|}{ Continuous and agile evaluation designed to meet the emerging demands of the clinical environment } \\
\hline Evaluation and feedback & $\begin{array}{l}\text { - Being agile to meet the emerging demands of the clinical } \\
\text { environment } \\
\text { - Understanding how health care providers perceive HIS } \\
\text { education and eventually its application }\end{array}$ & {$[5,6,21]$} \\
\hline
\end{tabular}

\section{Invest in Engaging and Understanding Learners in the Clinical Context Theme}

The Invest in engaging and understanding learners in the clinical context theme includes both understanding learners' needs and understanding what incentives may best enable learner participation in HIS education.

Several papers have identified the importance of assessing the current capability level of learners in terms of clinical and technical skills to tailor learning accordingly, including providing adequate staff and time for education. Many health care providers received their education as health care providers before information technology became ubiquitous and, therefore, may lack the essential technical skills required to use an HIS effectively [1]. Benwell et al [23] reported that learners often felt that the HIS training sessions failed to address their learning needs, as the program was either too simplistic or advanced. This point was further reinforced in a study that examined traditional forms of education approaches, assuming that each health care provider shared the same knowledge and skill level.
However, the authors discovered that the skillset of care providers differed based on their experience and educational levels [26,27]. In another peer-reviewed paper, the educational team at a hospital designed a course for health care providers with average computer skills.

The curriculum timing was based on an end-user with average computer skills: someone able to use a mouse and familiar with windows functionality. The design was frustrating to the advanced computer users because they were "slowed down" and frustrating to students with minimal skills because content was covered much too fast. Most staff attended training in 8-hour blocks, compounding this issue. Evaluations indicated that the number of hours spent in the classroom was over-powering and not conducive to learning. Staff reported feelings of burned out and too much content to absorb. [ 21 ]

Previous experiences with computers and the perceptions that learners bring with them regarding the value of technology influence their receptiveness during training sessions [21]. 
Edwards et al [4] stated that pretraining enabled those health care providers who needed it to gain baseline familiarity and improved their performance. Furthermore, Bredfeldt et al [1] reported:

\section{Trainees who are proficient at problem list management may have already reached the functional ceiling, leaving no room for improvement. In contrast, while some training participants were very practical at medication list management, there was still room for improvement. [ 1 ]}

Adequate technology literacy and general competencies of health care staff have been identified as critical factors for implementing HIS systems [16,26]. Without these, further education sessions may be required to support health care providers before they engage in learning specific to HIS.

Four papers discussed the significance of providing incentives to help health care staff expand their information technology competencies to encompass new skills $[1,6,17,18]$. A study by O'Brien [18] asserted that to cover the expense of adequate training and replacement nurses, the organization provided incentives to staff to complete their training on days they were not scheduled to work. In addition, the organization has developed an incentive program to encourage staff to fill in for colleagues who were participating in training or to attend a training class in the evening or weekend at full pay. In another study, providers were recognized for their time by being eligible for continuing medical education credits $[1,6]$.

\section{Maximize the Transfer of Learning to Care Theme}

The theme of Maximize the transfer of learning to care encompasses providing hands-on practice, integrating real-life case scenarios, engaging key stakeholders and staff champions, and scheduling education sessions close to the actual use of the system, all of which contribute to a learner-centric approach and a more successful HIS implementation (Table 2).

Many papers stressed the importance of providing learners with significant amounts of time to engage in hands-on activities [4]. Interaction with the HIS was a key priority among all participants across several studies $[4,6,17,25]$. Participants were provided with an overview of the key features of the system, using a combination of lectures and practical exercises, thus enabling the learners to gain hands-on experience using the new system [25]. In addition, hands-on activities enabled health care providers to gain more practice and become familiar with the system and have an opportunity to ask questions [6].

Class participants indicated that the hands-on exercises were the most useful portion of the class, and they appreciated the ability to build things in class that could be used in the clinic. [1 ]

This finding corresponds with concerns from health care managers that learners should be competent in using HIS in their work setting [4]. By providing an opportunity to deliberately practice with the system, active learning is encouraged, thereby increasing learners' confidence [4]. Nicklaus et al [17] described that hands-on experience allows for the practical application of the concept and enables distraction-free instruction. This approach encourages learners to set the pace of their learning without becoming overwhelmed with a lot of content in a short period of time while increasing their confidence and competency levels [17]. By promoting a self-regulated learning principle, effective learning can be achieved by empowering learners to take part in their own learning process, set their own goals, and challenge their critical thinking skills [17]. Self-regulated learning is defined as a cyclical process that enables the learner to guide their goal-directed activities, evaluate their performance, and then reflect on the outcomes [28]. McAlearney et al [7] asserted the following:

...training programs that include opportunities for
learners to observe others using the EHR system, and
those that provide active learning opportunities,
should enhance the learning process because they
give learners opportunities to develop positive
perceptions about their own abilities related to using
the EHR. [ [ ]

This point was reinforced in a study by Bredfeldt et al [1], stating that classroom-based training and hands-on activities were associated with the improved utility of using the new system. The authors noted that a live EHR environment allowed staff and clinicians to build tools they could use when they returned to the clinic and the use of ancillary resources [1]. Through continuous interaction with the system, learners reduced their cognitive effort associated with performing the task [16].

In addition, several studies have found that educational programs that incorporate real case scenarios, with an emphasis on clinical workflow enhance outcomes [25,26]. Interactive scenarios presented with a mini case study highlighted the importance of new HIS elements, enabling the care providers to better understand the new updates involved with the HIS and the manner in which they needed to document [22]:

\section{A hybrid teaching method that entailed both e-learning and a supplemental education session providing face-to-face personal communication, case examples, and examples of errors improved timeliness, completion and accuracy of nursing documentation significantly. [ 16]}

Studies have highlighted the importance of developing expertise-specific scenarios that are relevant to health care providers [25]. The use of various approaches may appeal to individual learning needs, with learners appreciative of relevant clinical scenarios in particular [25]. The scenarios were designed to reflect the daily workflow process and enabled learners to visualize how the HIS can potentially be used in their work environment [22]. Furthermore, the scenarios provided each learner with further exposure to the workflow and an opportunity to critically reflect through the different processes [22].

The literature findings described the importance of and positive changes in engaging key stakeholders and staff champions in achieving targeted organizational change. Super users (expert users who have received supplementary education and are capable of educating other staff) were found to play a critical role in providing unit-level assistance and reducing the need for expensive external education and training $[18,25]$. They act 
as facilitators in each area or department, supporting and educating new staff $[18,26]$. McAlearney et al [7] reported:

\section{...when learners observe others successfully using the EHR, their efficacy expectations are increased because of their corresponding beliefs that they also possess the capabilities to master the EHR system. [ 7]}

The authors emphasized the importance of positive behavior modeling (role modeling from peers in the work environment), which demonstrates effective approaches to help overcome these challenges. They acknowledged that engaging champions and super users may foster transformative learning and contribute to a learner-centric approach. In a study on training programs that leverage the skills of super users, it was reported that they contribute to better learning outcomes and meaningful use of the HIS [7]. Pantaleoni et al [6] described that the success of the training program was also attributed to the lead physician, as they provided guidance on the clinical context and knowledge of institutional workflows, such as the number of distinct provider workflows and how to group providers in a training session [6]. In addition, physicians were involved in the design and delivery of the training communication for hospital and staff leadership [6]. Pantaleoni et al [6] asserted that it is vital that the super user has an interest in education, institutional knowledge, and good communication skills.

In addition to the engagement of organizational stakeholders and staff champions, formalized education scheduled close to the actual use of the system was identified as beneficial to end users $[23,26]$. The study findings suggested that health care providers benefit from formal education only when it occurs in close proximity to their use of the HIS. Pantaleoni et al [6] emphasized the following:

Training classes should be offered 2 to 8 weeks prior to the change. Training that occurs greater than 8 weeks will likely not be remembered by the end-user. [6]

It has been noted that education delivered too early or too late could potentially waste resources and raise frustrations among staff $[23,26]$. Moreover, the authors stated that following 30 days of unit-based experience, most staff ultimately exhibit a similar skill level. Education that is scheduled in close proximity to the time of end-user use may facilitate the greatest impact on performance and knowledge acquisition [23,26]. Furthermore, formalized (instructor-led) education may not be needed for all learners, as some participants reported formal education to be inefficient and of little value; however, daily exposure to the HIS improved their performance [23].

\section{Continuous and Agile Evaluation Designed to Meet the Emerging Demands of the Clinical Environment Theme}

A review of the studies suggested that continuous evaluation supports an agile approach to meet the emerging demands of the clinical environment (Table 2).
Pantaleoni et al [6] described the need to conduct an evaluation of an HIS educational program:
We then conducted an evaluation of a pilot implementation of the eLearning course to ensure that the resources matched needs; were understandable, usable, and useful; and contributed to quality improvement of future HIS eLearning resources. [ 6 ]

Furthermore, McCain [21] stressed the value of evaluating educational programs continuously to identify course strengths and weaknesses in stimulating curriculum revisions. The authors emphasized that all HIS-related training and education programs should be continually updated to stay abreast of the evidence base and innovations.

\section{Future work must include expansion and optimization of the current modules, and targeted dissemination to support uptake in appropriate settings. If evidence-based strategies for training providers Health Information Technology (HIT) are lacking, appropriate and effective use of these technologies will be limited, and many costly and potentially powerful HIT projects may fail to improve the quality of healthcare. [ 21]}

Hence, the evaluation allowed educators to understand the need for change in work processes and practices and an opportunity to establish mechanisms to share learning across the organization.

Importantly, although continuous evaluation can lead to learner-centric education delivery, HIS data can also be leveraged to prioritize interventions for system optimization and workflow redesign and to identify struggling learners who may require additional training or support [5]. In a study by Kadish et al [5], clinicians requested individualized training after several rounds of group training to improve their own efficiency in the EMR. Ensuring that the educational content was relevant and applicable to all learners was challenging, as individual skill sets in using the system varied among care providers. This study accentuated the importance of capturing data over time to inform continuous and personalized assistance to optimize the use of the HIS after initial training. Individualized education ensured that educators were able to adapt the content to accommodate the diversity of clinical practice at the individual and group levels to improve the competency and confidence of learners in the use of HIS to find clinical information [5].

\section{Research Question 2: Measures and Outcomes Used to Assess the Effectiveness of Education and Its Impact on the Implementation of HIS}

Twelve papers presented the results of their training evaluation [1,4-6,16-21,23,24]. As training approaches and outcomes varied across studies, each approach will be briefly discussed (Table 3 ), followed by measures and statements of education outcomes associated with each educational approach. The classification of educational outcomes will be guided by Kirkpatrick-Barr. 
Table 3. Summary of the 12 studies that assessed the effectiveness of the education program.

\begin{tabular}{lll}
\hline Training approach and author & Measures & Outcomes
\end{tabular}

Pantaleoni et al [6]

Kadish et al [5]

Evatt et al [16]

O’Brien [18]

Kraus et al [20]
- Survey assessed providers' overall training experience, including trainer preparedness, course design, handouts, and the learner's overall readiness to use the system

- Providers were sent 2 surveys:

- The first survey was sent before training and used a 5-point Likert scale to measure confidence in the $\mathrm{EMR}^{\mathrm{a}}$ overall and in 5 key activities.

- Immediately after training, a second survey was sent to participants to evaluate the session and to gauge confidence in the same activities.

- Changes in time spent in various EMR activities before and after training were compared using a paired Wilcoxon test.

- Nurses completed a knowledge and attitude survey before and after education session:

- 10-item researcher-designed instrument

- Questions assessed knowledge regarding timeliness policy, area content, and information within areas

- Likert scales: testing attitude toward the completion of the $\mathrm{EHR}^{\mathrm{b}}$ nursing admission assessment

- $\quad$ Sampled charts of patients admitted to the 2 units before and after completion of the sessions:

- To evaluate the timeliness of completion, the time (in minutes) from patient admission to the unit to submission of the nursing admission assessment to the EHR was determined.

- Accuracy of documentation was assessed with regard to the accuracy of the past medical history.

- Physician survey was conducted 2 months after the physician order-entry go-live date.

- Measure the level of adoption of $\mathrm{CPOM}^{\mathrm{c}}$ : percentage of the utilization of HIS ${ }^{\mathrm{d}}$ by CPOM of physicians.
- High physician satisfaction with the program (level 1)

- Positive effect on confidence in knowledge acquired (level 2a)

- Participants reported an increase in confidence across all activities (level $2 a$ ), and almost all providers agreed that the training enhanced their efficiency (perceived; level 3).

- A reduction in the overall time in the EMR system was observed. Participants reported becoming more efficient with the use of the EMR (level 3).

- Nurses' attitudes (level 2a) and knowledge (level 2b) regarding completion of the EHR nursing assessment admission assessment improved significantly.

- Following the educational session, the mean time to completion of the EHR nursing admission assessment decreased (level 3 ).

- Timeliness, completeness, and accuracy of assessment documentation (after the session) were improved significantly after use of a hybrid approach (level 3).

90\% agreed that the EMR system made it easier for them to do their work (level 1).

- Medication errors caused by illegibility and transcription were eliminated completely (level 3 ).

- $\quad$ Staff also have found that the EMR system makes their jobs more efficient (level 3).

- Patient satisfaction scores for the overall satisfaction with care climbed to their highest levels (level $4 b$ ).

- Physician adoption reached the first-year goal of $40 \%$ physician entry in the first month and stabilized at $75 \%$ within a year.

- The impact has been noted in pharmacy, where the average time from order to pharmacist verification decreased from $90 \mathrm{~min}$ before CPOM to $17.9 \mathrm{~min}$ a year later (level 3).

- The resulting order sets and their increasing use in clinical care can be considered another measure of success. 


\begin{tabular}{cl}
\hline Training approach and author & Measures \\
\hline Bredfeldt et al [1] & $\begin{array}{l}\text { Evaluated } 2 \text { outcome measures in the EHR data for } \\
6 \text { months before and after training: }\end{array}$ \\
& $\begin{array}{l}\text { Proportion of visits in which either the problem } \\
\text { list or the medication list was modified } \\
\text { Modifying the problem list included adding or } \\
\text { deleting problems from the problem list or at- } \\
\text { taching comments to existing problems on the } \\
\text { list }\end{array}$
\end{tabular}

- $\quad$ Modifying the medication list included marking medications as chronic, removing inactive medications, or marking the medication list as reviewed

Benwell et al [23]

- Questionnaire (10-point Likert scale and dichotomous scale)

- To rate their self-perceived skill level using computers in general versus BOSSnet (digital medical record), the usefulness of the ICT $^{\mathrm{e}}$ training session and their willingness to train others

- The time taken to complete all tasks (efficiency) and the number of incorrect mouse clicks (accuracy) used to complete each task were recorded during the education session.

Nicklaus et al [17]

- Observations to measure the effectiveness of training

Rudd et al [24]

McCain [21]

- $\quad$ Likert scale and open-ended questions

- Rating how well objectives were met and clarity of information, in addition to sharing course strengths and suggestions for improvement
Outcomes

- Training was related to a small but significant increase in the use of key EHR capabilities:

- Participants increased their use of both the problem list from $22 \%$ to $24 \%$ of visits and their use of the medication list from $41 \%$ to $45 \%$ of visits after the education session (level 3 ).

- A significant improvement in both efficiency and accuracy for all participants during the session was observed (level $2 b$ ).

- The greatest improvements in task performance followed daily ward-based experience using BOSSnet rather than formalized training.

- $\quad$ Learners were satisfied with the learning laboratory as it provided an opportunity for them to practice and understand the system (level 1).

- They reported that scenario-based practice time stimulated realistic documentation and that they began to better comprehend the information.

- $\quad$ Respondents reported high satisfaction with the overall content of the course and with the e-learning modules (level 1).

- Blended e-learning course participants gave positive feedback about the course structure (level 1), and their knowledge of HIS competencies.

- Participants experienced strong learning gains in both, although learning gains were somewhat greater in the in-person course (level 2b).

- Reduction in training time was observed.

- Participants liked being able to complete the training at their own pace and immediately practice the information learned (level 1). 


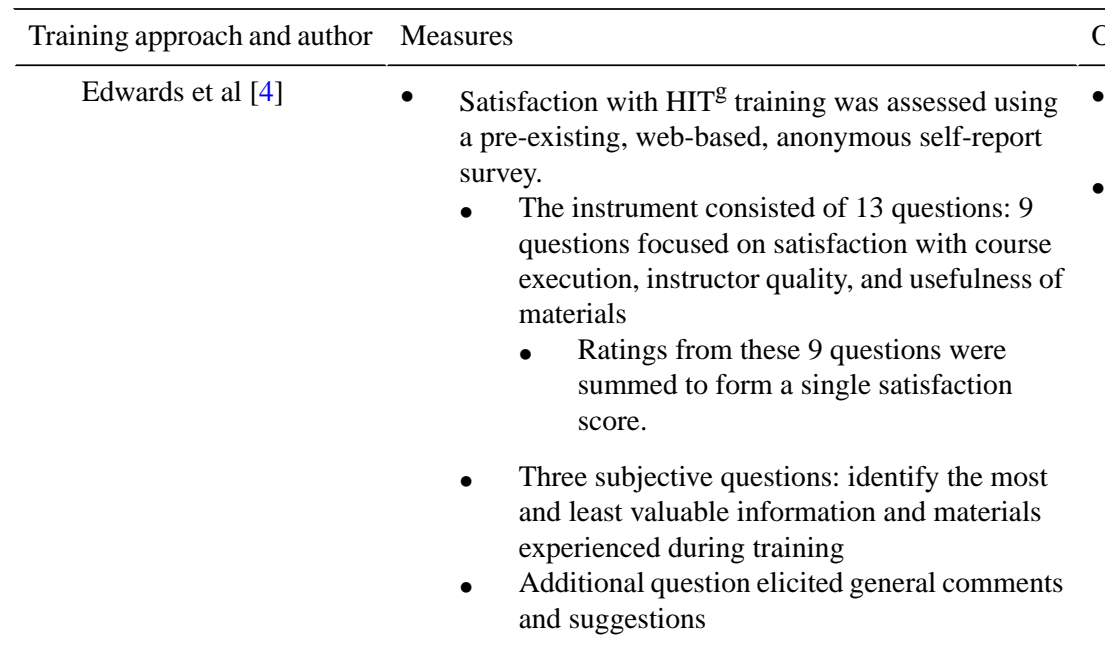

\section{Simulation training}

Vuk et al [19]
Outcomes

- Learners were equally satisfied with both methods: instructor-led and blended learning BL (level 1).

- Instructor-led participants found the training to be valuable (level 1), particularly the system functions and navigation.
Simulation training enhanced physicians' and nurses' levels of self-confidence and preparedness to use EMRs (level 2a). immediately after simulation training

- Assessed their perceptions about the importance of EMRs in improving patients' safety and their confidence and preparedness level to use EMRs

\footnotetext{
${ }^{\mathrm{a} E M R}$ : electronic medical record.

${ }^{\mathrm{b}} \mathrm{EHR}$ : electronic health record.

${ }^{\mathrm{C}} \mathrm{CPOM}$ : computerized physician order management.

${ }^{\mathrm{d}} \mathrm{HIS}$ : health information system.

e ICT: information computer technology.

${ }^{\mathrm{B}} \mathrm{BL}$ : blended learning.

${ }^{\mathrm{g}}$ HIT: health information technology.
}

\section{Discussion}

\section{Current State of HIS Education Programs}

This study identified critical knowledge gaps in our understanding of the most effective strategies and approaches in enabling health care providers to optimally use an HIS system. We only identified 17 studies that examined the effects of different education tactics in a hospital environment. This paucity of literature indicates the maturity of the topic area and emphasizes the need to establish a baseline understanding of HIS education strategies during and post implementation. This study provides an understanding of the current landscape of these programs and important insights into successful education development and improvement.

HIS education and training have been identified as potential key facilitators in ensuring effective and optimal use of technology and can have a positive impact on HIS implementation, efficiency, and patient care. Competency in HIS is now an essential clinical skill, and health care providers and staff who lack proficiency and efficiency may face challenges in performing clinical tasks [29]. Despite this, many organizations underestimate education and training needs and the time required for effective education [10]. Unsuccessful transitions are also because of a lack of understanding of what learners expect to gain from training and failure to link training to HIS implementation. Furthermore, a lack of adequate education may increase the risk of users creating workarounds that limit the advantages of HIS and potentially hold the organization back [10].

Upon review of the numerous instruments employed in the reviewed literature, it is apparent that no standardized tools have been adopted yet to assess learner outcomes of education programs. The majority of authors used self-constructed, nonvalidated scales and defined their results in qualitative terms. This limits all future efforts to compare and analyze evidence on the effectiveness of the HIS curriculum. More studies with standardized outcome measures and assessment tools are required to support recommendations on the most effective approaches in enabling providers to optimally use an HIS.

Fortunately, HIS training is beginning to embrace a learner-centric paradigm, and HIS education can be informed by existing educational frameworks such as Kirkpatrick and Moore. For example, Kirkpatrick and Moore's frameworks are focused on evaluating health care provider education and have become a commonly cited reference when assessing educational outcomes. Although these frameworks provide a good source of reference for evaluating the impact of learning and development, these frameworks do not provide sufficient direction for designing and sustaining an HIS education program. In particular, the frameworks do not take into account a wide array of factors, including those associated with the organization, individuals, teams, and the overall design of the 
education itself, all of which can influence the effectiveness of the educational program before, during, or after education delivery. Similarly, the experiential learning theory by Kolb focuses on learning at the individual level, a helpful but insufficient perspective to guide planning for HIS education across an organization. Finally, and importantly, none of these frameworks are grounded in evidence unique to HIS education.
Given many of the considerations that are unique to HISs and the limited applicability of existing educational frameworks, the authors developed a new framework for HIS education that guides the adoption of the most effective education strategies used to equip health care providers with the skills required to work effectively in a clinical environment. To address these gaps, the Accelerating the HIS Learning Cycle Framework in Figure 2, with the 5 fundamental elements, was developed from the data from this study.

Figure 2. Accelerating the health information system learning cycle framework. HIS: Health Information System.

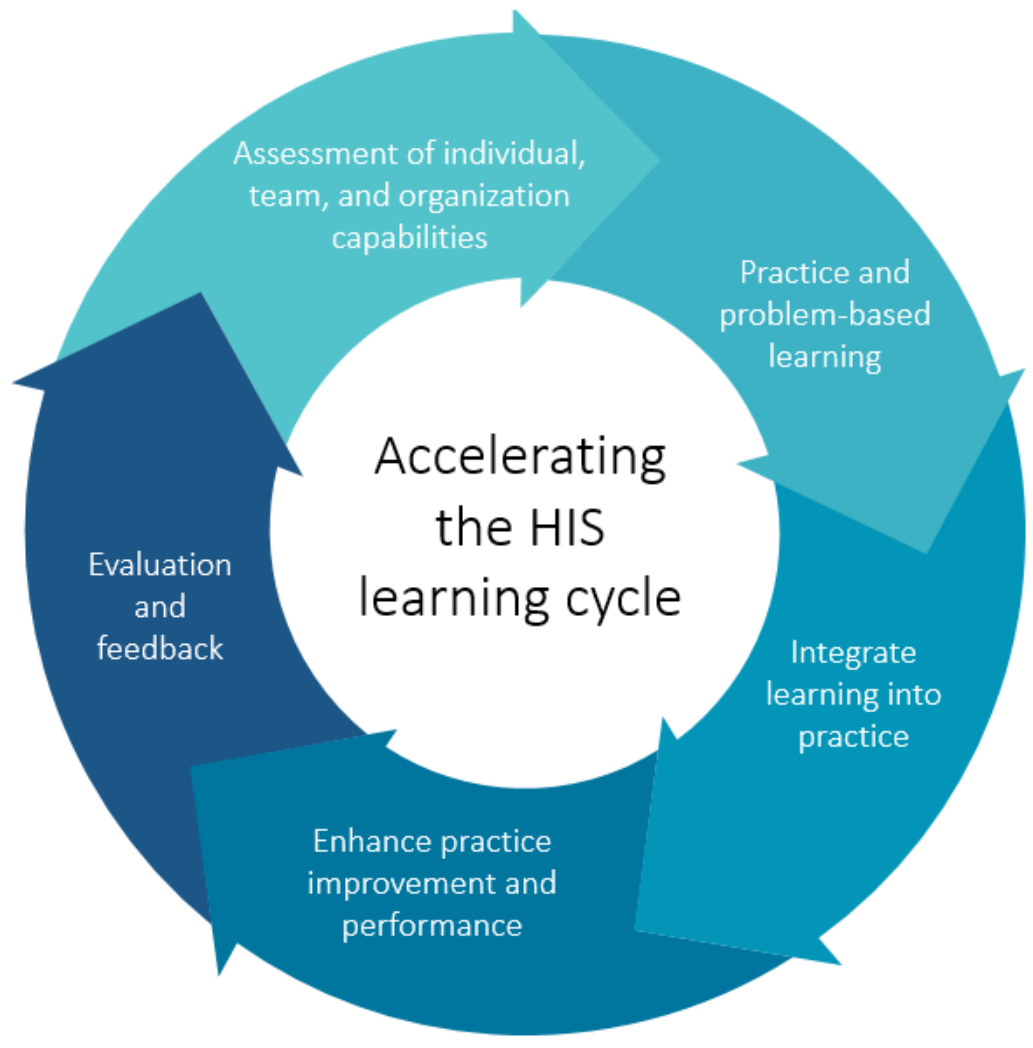

\section{Research Question 3: Most Effective Approaches in Enabling Individuals to Optimally Use an HIS}

\section{Assessment of Individual, Team, and Organization Capabilities}

The assessment of the current capability of learners (individuals and teams) before the delivery of training appears to be a critical facet of effective HIS implementation. As learners progress in their environment and acquire new skills and methods of engaging in their ecosystem, education should be adapted to address their learning needs. Hence, it is worth acknowledging that there may be different levels of HIS knowledge and adoption among providers. Terry et al [30] and Harton et al [31] noted that although there is variability regarding the influence of previous technical knowledge on perceptions of EMR adoption, learners with lower digital literacy may require extra sessions to learn the functionality of the computer and the processes necessary for clinical practice. This finding is particularly important as health care systems evolve to leverage HISs to support clinicians' adaptation to the new workflows and integration of this technology into their clinical practice. Despite the value placed on interprofessional learning, the literature has primarily focused on individual learning and a dearth of evidence has been provided on team-based learning. Future research exploring interprofessional education could provide greater insights into designing an effective educational program.

Culture pervades learning, and to meet the needs of diverse learners, issues revolving around the social and cultural dimensions of task design, structuring of content, and communication channels must be considered when designing a curriculum [32]. Culturally responsive pedagogy (CRP) recognizes learners' differences and stresses that the cultural congruence of an instructional environment increases learners' success [33]. A study from the University of British Columbia revealed that learners who are culturally diverse have a tenuous relationship with institutions that focus their curriculum on traditional, Eurocentric, and normative approaches [33]. These approaches tend to neglect learners from marginalized cultural backgrounds by disregarding their cultural habitus, leading to a cultural discontinuity for learners and the organization [33]. Rijal [34] reported that learning organizations moving toward a culture that encourages openness, creativity, experimentation, and tolerance for mistakes will enhance learning outcomes. An 
important part of a learning organization is being able to create new knowledge and use it to capitalize on new opportunities [35]. CRP has been hypothesized to connect all facets of learning with each other on emotional, social, mental, and physical levels [33]. In this framework, CRP is an important element in understanding individuals' and organizations' needs.

\section{Practice and Problem-Based Learning}

This study surfaced the relevance of problem-based learning in HIS education and training. A majority of the papers focused on a task-based learning approach to training, where learning is built based on predefined tasks addressed in clinical practice. Unfortunately, a task-based approach can lead to learners being dependent on instructors and support tools to provide them with guidance to perform the task, rather than encouraging them to critically think about how to approach the task [36]. Focusing on a narrow learning parameter without examining the larger context of the HIS system may not be sufficient to successfully transform learners from the existing approach to the new electronic documentation [17]. Problem-based learning provides a promising avenue for delivering an optimal learning experience while fostering an active independent learning attitude in learners. This learning approach enables learners to internalize knowledge through a process of solving clinical problems and stimulate deeper thinking with an emphasis on how and why questions [36]. Education that is at the appropriate skill level of learners and focused on a problem-based learning approach may encourage learners to critically reflect and attempt to understand not only the tasks themselves but also the concepts and mechanisms underlying the tasks.

This study underscores the importance of incorporating hands-on practice as part of education to increase learners' confidence and competency in successfully using the HIS system. In a review by Younge et al [37], the authors asserted that hands-on practice addressed the learner's level of computer literacy, which also relates to their ability regarding the ease or difficulty of using HIS. Similarly, Youssef [10] contended that hands-on experience enables learners to develop realistic expectations of what the HIS is able to offer. Thus, learners are able to strengthen the connection between personal experiences, learning content, knowledge, and a concrete task, resulting in better comprehension of abstract concepts [38].

\section{Integrate Learning Into Practice}

Iterative assessment of learners' performance with new scenarios enables learners to demonstrate their knowledge and their competency in using their knowledge to deal with the new and more difficult cases being presented. Practice-based learning strengthens learners' knowledge integration and application in a real-life setting [38]. Younge et al [37] noted that educating with materials, which provide opportunities for active learning and using assessments that evaluate what learners know (efficiency) and how they use existing knowledge to solve new problems helps to foster adaptive expertise. Learners highlighted real-life scenarios as a way to augment critical thinking by engaging in discussions. Hence, digital learning resources must be designed in a manner that offers better immersion while not increasing cognitive load [38].
Use of hands-on learning is consistent with the main phases of the experiential learning theory by Kolb [39]. The incorporation of hands-on practice and real case scenarios provides learners with an opportunity to deal with the workflows in clinical practice, which occurs when clinicians engage in an uncertain and unfamiliar context and allows learners to take an active role in the learning process. Using hands-on practice and case studies built on the 4 stages of the experiential learning theory would elicit evidence for changes in the cognitive process, learning, and behavior. This is critical in underpinning the design of an HIS curriculum and the role of educators and learners.

The clinical environment is an ideal setting to identify knowledge and skill gaps and then pursue learning with colleagues and instructors in a venture to fill these gaps. The authors advocate for the development of an interprofessional community of practice (CoP) as it facilitates the sharing of best practices and allows for the creation of new knowledge to advance the domain of HIS in clinical practice [40]. A CoP is built based on the assumptions of co-participation, where all learners from varied geographical locations engage in the activities of the community intending to facilitate meaningful learning [41]. As long as learners and instructors are present and engaged, an online community will evolve dynamically to meet their specific needs [41]. The digital space allows participants to share their experiences and knowledge in creative ways to cultivate new approaches to problems. When designing the HIS education strategy, this element of sustainability should be considered to enable individuals to optimally adopt and effectively use an HIS.

\section{Enhance Practice Improvement and Performance}

Another critical element as part of an educational strategy is identifying and engaging super users early in the project to help foster learning and understand the value of the HIS in clinical settings. Engaging super users in the development of an educational program enables the content to be tailored to specific provider needs, which, in turn, will contribute to the overall HIS adoption and successful implementation. The identification and engagement of champions and super users are rooted in the diffusion of innovation theory developed by Rogers [42]. Super users and champions are early adopters and innovators who adopt the HIS very early and take part in the dissemination of the new idea within the organization. They use the communication channels established to influence people's attitudes and accelerate the rate of adoption [42].

\section{Evaluation and Feedback}

Evaluation plans should not only evaluate the efficacy of the initial training but also use this information to inform plans to address the ongoing learning needs during and post-HIS education and implementation. In addition, ongoing evaluation can provide insights into emerging learning needs not only about the HIS system but also about emerging practice gaps and variations, which can help refine the goals and objectives and guide the implementation of the most effective education strategies. Through evaluation associated with HIS education and implementation, areas of significant strength can also be identified; for example, one part of the organization may demonstrate exceptional use of the HIS in practice. Positive 
deviance allows the organization to identify the top performers and foster analysis and discussion of such performance to elevate performance among other groups within the organization [43]. This approach characterizes not only the processes and practices that exist in top-performing groups but also the context in which they are implemented, such as the organizational culture and norms of behaviors [43]. Evaluation can be used to maintain and garner support for an education program in addition to assessing learner achievement.

\section{Limitations}

The findings of our scoping review should be examined in the context of the following limitations. Due to the nature of the scoping review, the quality of each study was not assessed. The age of the literature and the gap in publication dates may curtail the validity of the findings concerning the current landscape, as many of the previous papers were published in a different health care climate. Moreover, based on 5 studies that assessed the third level of Kirkpatrick, one was a perceived outcome in behavior, and only one of the studies assessed the highest level of Kirkpatrick-Barr (results). Given the nature of the topic being investigated, we excluded studies that discussed HIS education in academic institutions (eg, universities). Another limitation of this study is that we cannot confirm that we did not miss any relevant studies as the literature on the most effective approaches in enabling individuals to optimally use an HIS is heterogeneous. There is no standardized terminology in educational research, and the term used to describe the same ideas may vary depending on the author, thus limiting the retrieval of papers comprising important findings. The acceleration of the HIS learning cycle framework is emergent from this study and itself has not yet been validated.

\section{Conclusions}

This study supports the development of an HIS learning framework that educators can use to guide the design and development of HIS education and training during and postimplementation. Given the advances in HISs, health care organizations should be equipped with the essential tools to deal with the turbulence that embodies digital ecosystems and research into all facets of education that prepare health providers, teams, and the organization as a whole, for the rapidly changing nature of clinical environments. This framework is a novel addition to the literature and needs to be pilot tested to evaluate their feasibility and efficacy in health care education. We posit that to successfully transform care providers to use the new technology, best practices and training principles in HIS education that harness the nature of transformative learning must be pursued. Future efforts should examine the effectiveness of interprofessional education interventions, as the literature predominantly focuses on individualized learning. Finally, we encourage future studies to focus on iterative learning to better understand how providers continue to learn from the HIS postimplementation about key practice gaps.

\section{Acknowledgments}

The authors wish to thank Sharon Ambata-Villanueva for her support and thoughtful feedback on previous iterations of this manuscript.

\section{Authors' Contributions}

DW led the conceptualization and design of the review, data analyses, and revised all drafts of this manuscript for important intellectual content and clarity. MA developed the search strategy and conducted the search and provided feedback on the manuscript. KF, MA, SM, TJ, and TT contributed to the identification of papers and screening. ML, TJ, and SM collaborated on the thematic analysis of the collected data, drafting, and finalization of the manuscript. DW, ML, and MT have contributed to the development of ideas that were instrumental in surfacing and maturing many of the concepts contained in this study. They also served as content experts in validating the findings and revising all drafts. All authors have read and approved the final manuscript.

\section{Conflicts of Interest}

None declared.

\section{Multimedia Appendix 1}

PRISMA (Preferred Reporting Items for Systematic Review and Meta-analysis) scoping review checklist. [DOCX File, $31 \mathrm{~KB}-$ Multimedia Appendix 1]

\section{Multimedia Appendix 2}

Search strategy.

[DOCX File, 38 KB-Multimedia Appendix 2]

\section{References}

1. Bredfeldt CE, Awad EB, Joseph K, Snyder MH. Training providers: beyond the basics of electronic health records. BMC Health Serv Res 2013 Dec 2;13:503 [FREE Full text] [doi: 10.1186/1472-6963-13-503] [Medline: 24295150] 
2. AbouZahr C, Boerma T. Health information systems: the foundations of public health. Bull World Health Organ 2005 Aug;83(8):578-583 [ㅌRE Full text] [Medline: $\underline{16184276}$ ]

3. Keshavjee K, Bosomworth J, Copen J, Lai J, Kucukyazici B, Lilani R, et al. Best practices in EMR implementation: a systematic review. AMIA Annu Symp Proc 2006:982 [FREE Full text] [Medline: 17238601]

4. Edwards G, Kitzmiller RR, Breckenridge-Sproat S. Innovative health information technology training: exploring blended learning. Comput Inform Nurs 2012 Feb;30(2):104-109. [doi: 10.1097/NCN.0b013e31822f7f7a] [Medline: 21915046]

5. Kadish SS, Mayer EL, Jackman DM, Pomerantz M, Brady L, Dimitriadis A, et al. Implementation to optimization: a tailored, data-driven approach to improve provider efficiency and confidence in use of the electronic medical record. J Oncol Pract 2018 Jul;14(7):e421-e428. [doi: 10.1200/JOP.18.00093] [Medline: 29939808]

6. Pantaleoni JL, Stevens LA, Mailes ES, Goad BA, Longhurst CA. Successful physician training program for large scale EMR implementation. Appl Clin Inform 2015;6(1):80-95 [FREE Full text] [doi: 10.4338/ACI-2014-09-CR-0076] [Medline: 25848415]

7. McAlearney AS, Robbins J, Kowalczyk N, Chisolm DJ, Song PH. The role of cognitive and learning theories in supporting successful EHR system implementation training: a qualitative study. Med Care Res Rev 2012 Jun;69(3):294-315. [doi: 10.1177/1077558711436348] [Medline: 22451617]

8. Mclean E, Sedera D, Tan F. Reconceptualizing System Use for Contemporary Information Systems. In: 15th Pacific Asia Conference on Information Systems. 2011 Jul Presented at: CIS'11; 2011 July 7-11; Brisbane, Australia.

9. Shachak A, Kuziemsky C, Petersen C. Beyond TAM and UTAUT: Future directions for HIT implementation research. J Biomed Inform 2019 Dec;100:103315. [doi: 10.1016/j.jbi.2019.103315]

10. Youssef W. Evaluation of EHR training as a catalyst to achieve clinician satisfaction with technology in acute care setting. MSc Thesis. University of Victoria. 2013. URL: http://dspace.library.uvic.ca/bitstream/handle/1828/4827/

Youssef_Walid_MSc_2013.pdf?sequence=1\&isAllowed=y [accessed 2021-02-02]

11. Kumar S, Aldrich K. Overcoming barriers to electronic medical record (EMR) implementation in the US healthcare system: A comparative study. Health Informatics J 2010 Dec;16(4):306-318 [FREE Full text] [doi: 10.1177/1460458210380523] [Medline: 21216809]

12. Arksey H, O'Malley L. Scoping studies: towards a methodological framework. Int J Soc Res Methodol 2007 Feb;8(1):19-32. [doi: 10.1080/1364557032000119616]

13. Peters MD, Godfrey CM, Khalil H, McInerney P, Parker D, Soares CB. Guidance for conducting systematic scoping reviews. Int J Evid Based Healthc 2015 Sep;13(3):141-146. [doi: 10.1097/XEB.0000000000000050] [Medline: 26134548]

14. Tricco AC, Lillie E, Zarin W, O'Brien KK, Colquhoun H, Levac D, et al. PRISMA Extension for Scoping Reviews (PRISMA-ScR): Checklist and Explanation. Ann Intern Med 2018 Oct 02;169(7):467-473. [doi: 10.7326/M18-0850] [Medline: $\underline{30178033}$ ]

15. Shen N, Yufe S, Saadatfard O, Sockalingam S, Wiljer D. Rebooting kirkpatrick: integrating information system theory into the evaluation of web-based continuing professional development interventions for interprofessional education. J Contin Educ Health Prof 2017;37(2):137-146. [doi: 10.1097/CEH.0000000000000154] [Medline: 28562503]

16. Evatt M, Ren D, Tuite P, Reynolds C, Hravnak M. Development and implementation of an educational support process for electronic nursing admission assessment documentation. Medsurg Nurs 2014;23(2):89-95, 100. [Medline: 24933785]

17. Nicklaus J, Kusser J, Zessin J, Amaya M. Transforming education for electronic health record implementation. J Contin Educ Nurs 2015 Aug;46(8):359-363. [doi: 10.3928/00220124-20150721-02] [Medline: 26247658]

18. O'Brien MS. Implementation of the EPIC electronic medical record/physician order-entry system. J Healthc Manag 2006;51(5):338-343. [Medline: 17039692]

19. Vuk J, Anders ME, Mercado CC, Kennedy RL, Casella J, Steelman SC. Impact of simulation training on self-efficacy of outpatient health care providers to use electronic health records. Int J Med Inform 2015 Jun;84(6):423-429. [doi: 10.1016/j.ijmedinf.2015.02.003] [Medline: 25746460]

20. Kraus S, Barber TR, Briggs B, Kall G, Vernon TR, Moran B, et al. Implementing computerized physician order management at a community hospital. Jt Comm J Qual Patient Saf 2008 Feb;34(2):74-84. [doi: 10.1016/s1553-7250(08)34010-0] [Medline: 18351192]

21. McCain CL. The right mix to support electronic medical record training: classroom computer-based training and blended learning. J Nurses Staff Dev 2008;24(4):151-154. [doi: 10.1097/01.NND.0000320673.65824.db] [Medline: 18685473]

22. Topaz M, Rao A, Masterson Creber R, Bowles KH. Educating clinicians on new elements incorporated into the electronic health record: theories, evidence, and one educational project. Comput Inform Nurs 2013 Aug;31(8):375-9; quiz 380 [FREE Full text] [doi: 10.1097/NXN.0b013e318295e5a5] [Medline: 23774448]

23. Benwell N, Hird K, Thomas N, Furness E, Fear M, Sweetman G. Effectiveness and efficiency of training in digital healthcare packages: training doctors to use digital medical record keeping software. Aust Health Rev 2017 Oct;41(5):479-484. [doi: 10.1071/AH16090] [Medline: 27591794]

24. Rudd KE, Puttkammer N, Antilla J, Richards J, Heffron M, Tolentino H, et al. Building workforce capacity for effective use of health information systems: evaluation of a blended eLearning course in Namibia and Tanzania. Int J Med Inform 2019 Nov;131:103945. [doi: 10.1016/j.ijmedinf.2019.08.005] [Medline: 31561193] 
25. Brown CL, Reygate K, Slee A, Coleman JJ, Pontefract SK, Bates DW, et al. A literature review of the training offered to qualified prescribers to use electronic prescribing systems: why is it so important? Int J Pharm Pract 2017 Jun;25(3):195-202. [doi: 10.1111/ijpp.12296] [Medline: 27488258]

26. Bygholm A. Staff training on the use of health information systems: what do we know? Stud Health Technol Inform 2018;247:191-195. [Medline: 29677949]

27. Goveia J, Van Stiphout F, Cheung Z, Kamta B, Keijsers C, Valk G, et al. Educational interventions to improve the meaningful use of Electronic Health Records: a review of the literature: BEME Guide No. 29. Med Teach 2013 Nov;35(11):e1551-e1560. [doi: 10.3109/0142159X.2013.806984] [Medline: 23848402]

28. Sanders MR, Turner KM, Metzler CW. Applying self-regulation principles in the delivery of parenting interventions. Clin Child Fam Psychol Rev 2019 Mar;22(1):24-42. [doi: 10.1007/s10567-019-00287-z] [Medline: 30788658]

29. Stroup K, Sanders B, Bernstein B, Scherzer L, Pachter LM. A new EHR training curriculum and assessment for pediatric residents. Appl Clin Inform 2017 Oct;8(4):994-1002 [FREE Full text] [doi: 10.4338/ACI-2017-06-RA-0091] [Medline: 29241239]

30. Terry AL, Giles G, Brown JB, Thind A, Stewart M. Adoption of electronic medical records in family practice: the providers' perspective. Fam Med 2009;41(7):508-512 [FREE Full text] [Medline: 19582637]

31. Harton BB, Borrelli L, Knupp A, Rogers N, West VR. Integrating traditional nursing service orientation content with electronic medical record orientation. J Nurses Staff Dev 2009;25(5):229-235. [doi: 10.1097/NND.0b013e3181ba3bb4] [Medline: 19820534]

32. McLoughlin C. Inclusivity and alignment: principles of pedagogy, task and assessment design for effective cross - cultural online learning. Distance Educ 2006 Nov;22(1):7-29. [doi: 10.1080/0158791010220102]

33. Ragoonaden K, Mueller L. Culturally Responsive Pedagogy: Indigenizing Curriculum. Can J Higher Educ Rev 2017 Aug 27;47(2):22-46. [doi: 10.47678/cjhe.v47i2.187963]

34. Rijal S. The influence of transformational leadership and organizational culture on learning organization: A comparative analysis of the it sector. J Admin Bus Stud 2016 Jun 21;2(3):121-130. [doi: 10.20474/jabs-2.3.3]

35. Goh S. Toward a learning organization: the strategic building blocks. SAMJ 1998;63(2):15-22.

36. Takahashi Y. Problem-based learning and task-based learning: a practical synthesis. Kaohsiung J Med Sci 2008 Mar;24(3 Suppl):S31-S33 [FREE Full text] [doi: 10.1016/s1607-551x(08)70091-3] [Medline: 18364284]

37. Younge V, Borycki E, Kushniruk A. On-the-job training of health professionals for electronic health record and electronic medical record use: a scoping review. Knowledge Manag E-Learning 2015 Sep;7(3):436-469. [doi:

10.34105/j.kmel.2015.07.029]

38. Chen J. Developing a cycle-mode POED model and using scientific inquiry for a practice activity to improve students' learning motivation, learning performance, and hands-on ability. Interact Learn Environ 2020 Jan 20:1-13. [doi: $10.1080 / 10494820.2020 .1716023]$

39. Fewster-Thuente L, Batteson T. Kolb's experiential learning theory as a theoretical underpinning for interprofessional education. J Allied Health 2018;47(1):3-8. [doi: 10.1007/978-1-4419-1428-6 227] [Medline: 29504014]

40. Li LC, Grimshaw JM, Nielsen C, Judd M, Coyte PC, Graham ID. Evolution of Wenger's concept of community of practice. Implement Sci 2009 Mar 1;4:11 [FREE Full text] [doi: 10.1186/1748-5908-4-11] [Medline: 19250556]

41. Pringle R. Developing a community of learners: potentials and possibilities in web mediated discourse. Contemp Issues Technol Teach Educ Online serial 2002;2(2):218-233.

42. Greenhalgh T, Stramer K, Bratan T, Byrne E, Mohammad Y, Russell J. Introduction of shared electronic records: multi-site case study using diffusion of innovation theory. Br Med J 2008 Oct 23;337:a1786 [FREE Full text] [doi: 10.1136/bmj.a1786] [Medline: 18948344$]$

43. Bradley EH, Curry LA, Ramanadhan S, Rowe L, Nembhard IM, Krumholz HM. Research in action: using positive deviance to improve quality of health care. Implement Sci 2009 May 8;4:25 [FREE Full text] [doi: 10.1186/1748-5908-4-25] [Medline: $\underline{19426507]}$

\section{Abbreviations}

CRP: culturally responsive pedagogy

EHR: electronic health record

EMR: electronic medical record

HIS: Health Information System

PRISMA: Preferred Reporting Items for Systematic Review and Meta-Analysis 
Edited by G Eysenbach; submitted 30.09.20; peer-reviewed by A Shachak, A Bygholm, S Nagavally; comments to author 04.12.20; revised version received 05.01.21; accepted 16.01.21; published 24.02.21

Please cite as:

Jeyakumar T, McClure S, Lowe M, Hodges B, Fur K, Javier-Brozo M, Tassone M, Anderson M, Tripp T, Wiljer D

An Education Framework for Effective Implementation of a Health Information System: Scoping Review

$J$ Med Internet Res 2021;23(2):e24691

URL: https://www.jmir.org/2021/2/e24691

doi: $10.2196 / 24691$

PMID: $\underline{3625370}$

(CTharshini Jeyakumar, Sarah McClure, Mandy Lowe, Brian Hodges, Katharine Fur, Mariquita Javier-Brozo, Maria Tassone, Melanie Anderson, Tim Tripp, David Wiljer. Originally published in the Journal of Medical Internet Research (http://www.jmir.org), 24.02.2021. This is an open-access article distributed under the terms of the Creative Commons Attribution License (https://creativecommons.org/licenses/by/4.0/), which permits unrestricted use, distribution, and reproduction in any medium, provided the original work, first published in the Journal of Medical Internet Research, is properly cited. The complete bibliographic information, a link to the original publication on http://www.jmir.org/, as well as this copyright and license information must be included. 